\title{
Propriedades fisiológicas-funcionais das proteínas do soro de leite
}

\author{
Physiological-functional properties of milk whey proteins
}

Valdemiro Carlos SGARBIERI ${ }^{1}$

\section{R E S U M O}

O presente artigo coloca em destaque as propriedades multifuncionais das proteínas presentes no soro de leite bovino, a começar pelo colostro que contém essas proteínas em concentrações muito elevadas e que tem por função garantir a proteção e a imunidade dos recém-nascidos. Essas mesmas proteínas continuam no leite, porém em concentrações bastante reduzidas. A utilização dessas proteínas nas formas de concentrados e isolados protéicos evidenciam propriedades muito favoráveis à saúde no sentido de diminuir o risco de doenças infecciosas e também as consideradas crônicas e/ou degenerativas. Enfatizou-se as propriedades das proteínas do soro de leite e de peptídios delas resultantes no estímulo ao sistema imunológico, na proteção contra microrganismos patogênicos e contra alguns tipos de vírus como o HIV e o vírus da hepatite C, na proteção contra vários tipos de câncer, particularmente de cólon, na proteção da mucosa gástrica contra agressão por agentes ulcerogênicos, evidenciou-se várias linhas de ação protetora das proteínas de soro contra agentes condicionadores de problemas cardiovasculares. Com base em várias propriedades funcionais das proteínas do soro de leite, discutiu-se a vantagem e os benefícios de seu uso como suplemento alimentar para atletas e esportistas em geral. Os possíveis benefícios de vários fatores de crescimento celular, presentes no soro de leite também foram discutidos.

Termos de Indexação: proteínas do leite, leite, colostro, propriedades funcionais fisiológicas.

\section{A B S T R A C T}

This article emphasizes the multifunctional properties of the bovine milk whey proteins, starting with the colostrum where these proteins occur in high concentrations and are reputed as responsible for the protection and passive immunization of the newborn babies. The same proteins found in colostrum in high concentrations are found in milk although at much lower concentrations. The utilization of the milk whey proteins in the form

\footnotetext{
1 Departamento de Alimentos e Nutrição, Faculdade de Engenharia de Alimentos, Universidade Estadual de Campinas. Rua Monteiro Lobato, 80, 13083-970, Campinas, SP, Brasil. E-mail: sgarb@fea.unicamp.br
} 
of concentrates or isolates has been found to be highly beneficial to health in the sense of decreasing the risk of infectious as well as chronical and degenerative diseases. In this article emphasis was given to the properties of whey proteins in the form of concentrates or isolates, and their hydrolysates (peptides) as immunostimulants, inhibitors of pathogenic microorganisms and some viruses, including HIV and hepatitis C viruses. In the protection against tumor's development, particularly colon cancer and protection of the gastric mucosa against ulceration by agressive ulcerogenic agents. Various actions of the milk whey protein were pointed out as defense mechanisms for cardiovascular degenerative diseases. Several research work were discussed showing the benefit of using milk whey protein to counteract undesirable metabolic and immunological effect of excessive exercise. Finally the cell growth and regeneration stimulatory properties of the milk whey growth factors were pointed out.

Index terms: milk, proteins, milk, colostrum, physiological-functional properties.

\section{N T R O D U Ç Ã O}

O leite, produto de secreção das glândulas mamárias é um fluido viscoso constituído de uma fase líquida e partículas em suspensão, formando uma emulsão natural, estável em condições normais de temperatura ou de refrigeração. Possui elevado valor nutritivo, sendo o único alimento que satisfaz às necessidades nutricionais e metabólicas do recém-nascido de cada espécie1.

Os macrocomponentes do leite bovino são a água (87,30\%), a lactose $(4,90 \%)$, gordura $(3,80 \%)$, proteínas $(3,30 \%)$ e minerais $(0,72 \%)$. As partículas suspensas na fase líquida do leite são gotículas de gordura e micelas de caseína. 0 leite bovino é comercializado em sua forma líquida integral ou desengordurada e pasteurizado ou esterilizado. Essas mesmas formas são também comercializadas desidratadas, leite em pó.

O soro de leite pode ser obtido em laboratório ou na indústria por três processos principais 2,3: a) pelo processo de coagulação enzimática (enzima quimosina), resultando no coágulo de caseínas, matéria-prima para a produção de queijos e no soro "doce"; b) precipitação ácida no $\mathrm{pH}$ isoelétrico (pl), resultando na caseína isoelétrica, que é transformada em caseinatos e no soro ácido; c) separação física das micelas de caseína por microfiltração, obtendo-se um concentrado de micelas e as proteínas do soro, na forma de concentrado ou isolado protéico.
A relação caseínas:proteínas do soro é bastante variável entre as espécies de mamífero ${ }^{4}$. Esta relação é de 80,0:20,0 (\%) no leite bovino, de 20,0:80,0 (\%) no leite humano, 80,0:20,0 (\%) no leite de búfala e 82,2:15,8 (\%) no de cabra. Observa-se que no leite humano a proporção de proteínas de soro é 4 vezes a das caseínas, comparadas com as do leite de vaca e de búfala.

Outro aspecto muito importante a considerar sobre o leite, como primeiro e único alimento dos recém-nascidos, é que a primeira secreção das glândulas mamárias, após o parto, tem composição muito diferente do leite e recebe o nome de colostro. O colostro é um líquido amarelado, mais viscoso que o leite e a sua composição varia muito nas primeiras $72 \mathrm{~h}$ após $\mathrm{o}$ parto ${ }^{5}$. A Tabela 1 mostra a variação de composição do colostro bovino nas primeiras $72 \mathrm{~h}$ comparada com a composição do leite já estabilizado.

Observa-se (Tabela 1) que a composição do colostro bovino (3h pós-parto) é bem diferente após $72 \mathrm{~h}$ e muito diferente do leite como é consumido. Gordura, proteína total, proteínas de soro e minerais diminuem com o passar do tempo, enquanto que as caseínas e a lactose aumentam.

Nota-se na Tabela 2 como a concentração $(\mathrm{mg} / \mathrm{mL})$ das principais proteínas do soro decresce no colostro no período de $3 \mathrm{~h}$ a $72 \mathrm{~h}$, e suas concentrações no leite bovino já estabilizado 5 . Observa-se que todas as proteínas: imunoglobulina $\mathrm{G}(\lg \mathrm{G})$, imunoglobulina A $(\lg A), \propto$-lactalbumina 
( $\propto$-La), $\beta$-lactoglobulina ( $\beta$-Lg), albumina de soro bovino (BSA), lactoferrina (Lf) e lactoperoxidase (Lp) diminuem significativamente de concentração, na passagem do colostro para leite normal de consumo.

A IgG é a predominante no colostro e no leite bovino e, dentre as demais proteínas, a $\beta$-Lg, a $\propto$-La e a BSA são as predominantes.

A elevada concentração das proteínas de soro no colostro é muito importante, uma vez que as imunoglobulinas ( $\lg G$ e $\lg A$ ) transferem imunidade passiva ao recém-nascido, enquanto que as demais proteínas do soro, coletivamente, promovem o desenvolvimento e a maturação dos tecidos epiteliais do sistema gastrointestinal, ainda não completamente desenvolvido funcionalmente. Protegem ainda contra bactérias e vírus deletérios à saúde do bebê.

Tabela 1. Variação na composição percentual do colostro bovino, comparada com a do leite bovino.

\begin{tabular}{lccc}
\hline \multirow{2}{*}{ Componentes (\%) } & \multicolumn{3}{c}{ Colostro (Tempo pós-parto) } \\
\cline { 2 - 3 } & \multicolumn{1}{c}{$3 \mathrm{~h}$} & $72 \mathrm{~h}$ & Leite bovino \\
\hline Gordura & 6,80 & 3,72 & 3,50 \\
Proteína total & 9,42 & 4,68 & 3,20 \\
Proteínas de soro & 8,50 & 1,60 & 0,50 \\
Caseínas & 0,92 & 3,18 & 2,73 \\
Lactose & 2,38 & 4,27 & 4,60 \\
Cinza & 1,02 & 0,74 & 0,70 \\
Sólidos totais & 19,62 & 13,41 & 12,00 \\
\hline
\end{tabular}

Fonte: Heng ${ }^{5}$.
Comparação interessante poderá também ser feita quanto às concentrações de algumas das principais proteínas do soro (Tabela 3) entre os leites bovino e humano. Nota-se que a $\beta$-lactoglobulina, predominante no leite bovino, praticamente não aparece no leite humano. As demais proteínas de soro aparecem também em maior concentração no leite humano.

Do ponto de vista aminoacídico (aminoácidos essenciais), as proteínas de soro apresentam quase todos os aminoácidos essenciais em excesso às recomendações, exceto pelos aminoácidos aromáticos (fenilalanina, tirosina) que não aparecem em excesso, mas atendem às recomendações para todas as idades. Apresentam elevadas concentrações dos aminoácidos triptofano, cisteína, leucina, isoleucina e lisina.

As proteínas do soro de leite são altamente digeríveis e rapidamente absorvidas pelo organismo, estimulando a síntese de proteínas sangüíneas e teciduais a tal ponto que alguns pesquisadores $^{6-8}$ classificaram essas proteínas como proteínas de metabolização rápida fast metabolizing proteins, muito adequadas para situações de estresses metabólicos em que a reposição de proteínas no organismo se torna emergencial.

Tabela 2. Concentração de proteínas de soro no colostro e no leite bovino $(\mathrm{mg} / \mathrm{mL})$.

\begin{tabular}{lccccccc}
\hline $\begin{array}{l}\text { Tempo } \\
\text { Lact.(Horas) }\end{array}$ & IgG & IgA & $\propto$-La & $\beta$-Lg & BSA & Lf & Lp \\
\hline 3 & 45,00 & 7,08 & 5,97 & 40,50 & 5,07 & 3,06 & 3,46 \\
12 & 61,50 & 9,55 & 8,40 & 39,88 & 5,21 & 4,28 & 4,29 \\
24 & 40,00 & 6,98 & 8,56 & 26,54 & 1,97 & 1,77 & 2,45 \\
36 & 15,00 & 3,17 & 6,42 & 18,47 & 1,20 & n.d. & 1,00 \\
48 & 13,60 & 0,56 & 8,12 & 19,42 & 1,15 & 0,94 & n.d. \\
60 & 15,80 & 0,56 & 8,12 & 19,42 & 1,15 & 0,94 & n.d. \\
72 & 6,00 & 0,12 & 2,36 & 6,18 & 0,44 & n.d. & n.d. \\
Leite & 0,50 & 0,09 & 2,00 & 4,00 & 0,28 & $0,02-$ & 0,03 \\
& & & & & & 0,35 & \\
\hline
\end{tabular}

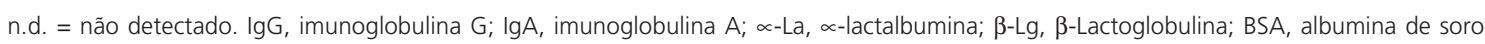
sangüíneo; Lf, lactoferrina; Lp, lactoperoxidase. 
Tabela 3. Quantidades, em gramas por litro, das principais proteínas de soro lácteo, do leite bovino e do leite humano.

\begin{tabular}{lcc}
\hline Proteínas de soro $(\mathrm{g} / \mathrm{L})$ & Leite bovino & Leite humano \\
\hline B-lactoglobulina & 3,2 & desprezível \\
$\propto$-lactalbumina & 1,2 & 2,8 \\
Soralbumina (BSA) & 0,4 & 0,6 \\
Imunoglobulinas & 0,7 & 1,0 \\
Lactoferrina & 0,1 & 0,2 \\
Lisozima & desprezível & 0,4 \\
\hline
\end{tabular}

Neste artigo, será dada ênfase às propriedades fisiológicas e funcionais que resultam em importante modulação metabólica e/ou inibição ou retardamento de processos patológicos ou do envelhecimento precoce em animais de experimentação e, provavelmente, na espécie humana.

\section{Atividade imunomoduladora}

Uma das propriedades funcionais fisiológicas mais estudadas e importantes das proteínas do soro de leite se relaciona com o seu poder imunomodulador. Já se comentou sobre a elevada concentração e o papel importante das imunoglobulinas do colostro na defesa dos recém-nascidos.

As imunoglobulinas do leite permanecem quase que integralmente no soro e continuam a desempenhar função importante, não somente no sistema gastrointestinal mas sistemicamente em todo o organismo.

Na década de 80, uma série de pesquisas desenvolvidas particularmente no Canadá9-12 mostraram que dietas à base de concentrados de proteínas de soro de leite bovino, não desnaturadas, promovia estímulo imunológico superior a um grande número de outras proteínas isoladas e testadas comparativamente, quanto ao poder de estimular a produção de imunoglobulina M (IgM) o baço, após estímulo antigênico (imunização) com um número conhecido de hemácias de carneiro.
Ao mesmo tempo em que se verificava aumento significativo da produção de imunoglobulina havia um aumento correspondente do tripeptídio glutationa ( $\gamma$-glutamilcisteinilglicina) no baço, no fígado e em vários outros órgãos.

Os pesquisadores canadenses associaram o poder imunoestimulante das proteínas do soro com a capacidade dessas proteínas estimular a síntese de glutationa, em virtude do elevado conteúdo de cisteína e de repetidas seqüências glutamil-cistina na estrutura primária dessas proteínas $^{12,13}$. Peptídios com a seqüência glutamil-cistina seriam formados na digestão dessas proteínas e absorvidos como tal, servindo de substrato para a síntese de glutationa. Esta, por sua vez, exerce um poder estimulatório sobre linfócitos capazes de sintetizar imunoglobulinas.

A eficácia das proteínas isoladas do soro de leite no sentido de melhorar a atuação do sistema imunológico foi também testada em humanos portadores do vírus HIV14,15. Esses vírus, mesmo quando a doença está sob controle, por efeito de medicação, causam um desequilíbrio dos linfócitos $\mathrm{TCD}_{4}{ }^{+}$(linfócitos de defesa do organismo) deixando prevalecer os linfócitos $\mathrm{TCD}_{8}^{+}$ ou linfócitos de ataque (Tkiller). Embora com número reduzido de sujeitos, 3 e 4 indivíduos, respectivamente, a administração de $10 \mathrm{~g}$ a $40 \mathrm{~g}$ diárias de proteínas de soro a esses indivíduos portadores de HIV elevou a concentração de glutationa nos linfócitos e o número de linfócitos $\mathrm{TCD}_{4}{ }^{+}$, melhorando as condições gerais dos pacientes, inclusive com ganho de peso de $2 \mathrm{~kg}$ a $7 \mathrm{~kg}$, no período de 3 meses de suplementação.

Estudos recentes ${ }^{16,17}$ realizados em Campinas, SP, comprovaram o poder imunoestimulante e estimulador da síntese de glutationa, em camundongos e em humanos, por preparados de proteína de soro bovino produzidos em escala piloto $^{2}$. Dietas contendo concentrado protéico de soro de leite (WPC) estimulou a síntese de imunoglobulina $M$ no baço e a síntese de glutationa no fígado em camundongo da linhagem 
$\mathrm{A} / \mathrm{J}$, mais do que qualquer outra proteína testada. Forte correlação linear positiva $(r=0,998)$ foi encontrada entre células do baço produtoras de IgM e concentração de glutationa no fígado. Em estudo prospectivo duplo-cego, 18 crianças entre 1 e 6 anos de idade, portadoras de HIV foram suplementadas com concentrado de proteína de soro de leite (WPC) ou placebo (maltodextrina) por 4 meses. Observou-se uma elevação nos níveis de linfócitos $\mathrm{TCD}_{4}{ }^{+}$, elevação da síntese de glutationa eritrocitária e redução na ocorrência de episódios infecciosos no grupo suplementado com WPC.

Além do concentrado e do isolado protéico de proteína de soro (WPC e WPI), respectivamente, ação imunoestimulatória tem sido demonstrada para proteínas isoladas do soro: imunoglobulinas, lactoferrina, lactoperoxidase, glicomacropeptídio (GMP). Este último só é encontrado no soro doce, como produto da ação da enzima coagulante quimosina sobre a к-caseína.

Além de estar presente no soro, a lactoferrina é secretada por neutrófilos, podendo estimular o crescimento de vários tipos de células do sistema imune como linfócitos, macrófagos/monócitos, além de estimular a resposta imune humoral na produção de anticorpos ${ }^{18}$.

\section{Atividade antimicrobiana e antiviral}

Atividade antimicrobiana e antiviral têm sido demonstradas para as proteínas do soro de leite lactoferrina, lactoperoxidase, $\propto$-lactalbumina e as imunoglobulinas.

A lactoferrina, bem como seu peptídio lactoferricina, inibem a proliferação e o crescimento de bactérias gran-positivas e gran-negativas, bem como leveduras fungos e protozoários por quelar (seqüestrar) o ferro disponível no ambiente, enquanto que a lactoperoxidase tem propriedade bactericida através da oxidação de tiocianatos em presença de peróxido de hidrogênio $\left(\mathrm{H}_{2} \mathrm{O}_{2}\right)^{19,20}$.

Hidrólise enzimática da lactoferrina libera peptídios com ação inibitória ao vírus da hepatite
C e com ação contra a bactéria Helicobacter pylori $^{21-22}$. A lactoferricina, peptídio formado dos resíduos 17-41, resultante da ação da pepsina sobre a lactoferrina, apresenta além da atividade antimicrobiana ${ }^{23}$, ação apoptótica sobre células da leucemia humana ${ }^{24}$.

Hidrólise enzimática (pepsina, tripsina, quimotripsina) permitiram o isolamento e a identificação de peptídios de diversos tamanhos moleculares e seqüências com atividade bactericida, a partir das proteínas $\beta$-lactoglobulina e $\propto$-lactalbumina ${ }^{21,25,26}$, sugerindo que essas proteínas do soro poderão exercer efeito antibiótico no organismo após hidrólise enzimática.

Propriedade bactericida também tem sido demonstrada em oligômeros de $\propto$-lactalbumina que podem se formar em meio ácido, na presença do ácido oléico ${ }^{27}$. Esses oligômeros poderiam se formar no estômago pela perda do $\mathrm{Ca}^{++}$ligado a essa molécula seguida da complexação com o ácido graxo monoinsaturado. Além da atividade antibiótica, esses oligômeros de $\propto$-lactalbumina apresentam também ação apoptótica sobre células cancerígenas.

\section{Atividade anticâncer}

Tem sido demonstrado, por vários pesquisadores, que concentrados de proteínas do soro de leite bovino, assim como várias de suas proteínas e peptídios, delas derivados, apresentam ação inibitória para diversos tipos de câncer em modelos animais e em culturas de células cancerígenas.

O câncer é uma doença complexa cuja indução e desenvolvimento dependem de inúmeros fatores. Várias pesquisas têm sido desenvolvidas nos últimos anos, tanto em modelos animais como em culturas de células que demonstram ação anticâncer das proteínas do soro de leite.

McIntosh et al. ${ }^{28-30}$ estudaram a ação de várias proteínas da dieta (proteínas de soro de 
leite, caseína, proteínas da carne bovina e da soja) contra o desenvolvimento de tumores de cólon induzidos pelo carcinógeno 1,2-dimetilhidrazina. Nestes estudos observaram que dietas contendo as proteínas do soro de leite inibiram o aparecimento e o crescimento de tumores de cólon de forma mais significativa que a caseína, as proteínas de carne bovina e as da soja, sendo a ordem de significância estatística: proteína do soro>caseína>carne>soja, podendo portanto concluir-se que as proteínas do soro (WPC) atuaram de maneira mais eficaz no combate à tumorigênese induzida, em roedores, que as demais proteínas testadas.

McIntosh et al. ${ }^{28}$ compararam a eficiência de dietas contendo 15\% de WPC, $15 \%$ de proteína de soja e dois outros tratamentos 15\% soja mais $5 \%$ lactoferrina ou $15 \%$ soja mais $5 \%$ $\beta$-lactoglobulina. Observaram que a suplementação da soja com $5 \%$ lactoferrina ou 5\% $\beta$-lactoglobulina resultou em inibição da formação de lesões pré-cancerígenas (focos de críptas aberrantes), tão eficientemente quanto o WPC, evidenciando a importância dessas duas proteínas do soro na inibição do processo de carcinogênese.

Recentes pesquisas realizadas em Campinas, SP, com câncer de cólon induzido em camundongos da linhagem A/J por azoximetano, confirmaram a eficácia das proteínas do soro de leite bovino (WPC) na inibição de lesões intestinais pré-cancerígenas (focos de críptas aberrantes) e desenvolvimento de tumores de cólon do tipo adenocarcinoma, bem como no estímulo à síntese de glutationa hepática e de imunoglobulina $\mathrm{M}$ (IgM) por células de baço ${ }^{31}$. Nesta pesquisa, comparou-se o poder antitumoral de quatro concentrados protéicos, a saber, um WPC preparado em Campinas, SP, em planta piloto ${ }^{2}$, um preparado de proteínas de soro (Immunocal), preparado e patenteado no Canadá, uma caseína comercial e um isolado de proteína de soja, também comercial. A dieta utilizada foi a AIN-93 com uma das proteínas citadas como única fonte protéica ( $20 \mathrm{~g}$ proteína/100g dieta). Não houve diferença entre as dietas para ganho de peso. $\mathrm{O}$ número e tamanho dos tumores foram significativamente maiores nos animais em dieta de proteína de soja, seguida da caseína e dos dois preparados de proteínas de soro, significativamente inferiores, em relação à caseína e à soja. Os dois preparados de soro não diferiram entre si, em nenhum dos parâmetros estudados. Esses resultados confirmaram os reportados por pesquisadores do Canadá, Austrália e outros países.

Outros pesquisadores constataram a capacidade inibitória das proteínas do soro de leite sobre o câncer de mama ${ }^{32}$, de cabeça e pescoço ${ }^{33}$ e sobre culturas de células cancerígenas ${ }^{34,35}$.

\section{Atividades antiúlcera}

Embora o leite e os produtos lácteos tenham sido, ao longo do tempo, os alimentos preferidos por pessoas com problemas gástricos (hiperacidez, azia, queimação estomacal, refluxo gástrico-esofágico), esses efeitos têm sido atribuídos, principalmente, às gorduras do leite e sua própria consistência física de emulsão líquida.

A partir do conhecimento de que as proteínas do soro de leite são ricas em aminoácidos sulfurados, particularmente cisteína, e que são capazes de promover, in vivo, aumento da síntese de glutationa além do fato de a glutationa ser importante na proteção dos tecidos epiteliais, iniciou-se em Campinas, SP, uma linha de pesquisa para explorar possível ação protetora das proteínas do soro de leite bovino na proteção da mucosa gástrica, contra vários agentes agressores.

Rosaneli et al. ${ }^{36-38}$ pesquisaram a ação de um preparado (WPC), produzido em planta piloto², na inibição da ação ulcerogênica do etanol absoluto, da indometacina (antiinflamatório não-esteroidal) e de fatores de estresse como imobilização e frio e estresse químico com reserpina.

Os resultados dessas pesquisas permitiram concluir que o WPC e seus hidrolisados enzimáticos protegem a mucosa estomacal de ratos contra as 
agressões do etanol absoluto e da indometacina, inibindo as lesões ulcerativas numa faixa de $50 \%$ a $80 \%$, em relação a um controle negativo (solução salina fisiológica). Comparou-se também com drogas específicas para o controle de úlcera gástrica, como a cimetidina e a carbenoxolona, cuja inibição foi da ordem de $80 \%$ a $90 \%$. Chegou-se ainda à conclusão, através de testes de bloqueios metabólicos com reagentes específicos, que as vias operantes no mecanismo de proteção parecem envolver substâncias sulfidrilas como cisteína, glutationa e provavelmente enzimas que dependem de grupos sulfidrilos em seu centro catalítico.

Envolve também o ciclo das prostaglandinas, tendo sua síntese na mucosa gástrica estimulada. As substâncias sulfidrilas, além da função redutora, protegem a mucosa através do seqüestro de radicais livres, que se formam em maior quantidade na presença dos agentes agressores. As prostaglandinas protegem a mucosa gástrica através do estímulo à produção de muco e de bicarbonato, que formam uma camada protetora da mucosa contra ulcerações.

Pesquisas recentes realizadas no exterior e pelo grupo de Campinas ${ }^{39-41}$, SP, permitiram concluir que uma das proteínas do soro ativa contra a ulceração gástrica é a $\propto$-lactalbumina e que a $\beta$-lactoglobulina não apresenta ação antiulcerogênica, em ratos.

\section{Proteção ao sistema cardiovascular}

Pesquisas realizadas no exterior e em Campinas, SP, mostraram que proteínas do soro de leite bovino podem atuar de várias formas, protegendo o sistema circulatório e cardíaco, podendo contribuir, desta forma, para a diminuição dos riscos de patologias cardiovasculares.

Algumas pesquisas ${ }^{42-45}$ evidenciaram efeito positivo das proteínas de soro na redução dos níveis de triglicérides e do colesterol sangüíneo e/ou hepático. Jacobucci et al.42,43 mostraram efeito positivo no abaixamento do colesterol sangüíneo, em ratos, semelhantemente à da proteína de soja, contrariamente à caseína que tende a aumentar a colesterolemia sangüínea e a lipidemia hepática.

Sautier et al. ${ }^{44}$ estudaram por 49 dias o efeito, em ratos, de dietas contendo $23 \%$ de uma das seguintes fontes de proteína: proteínas de soro de leite, caseína, proteínas de soja ou de girassol. Observaram que os níveis de colesterol foram mais altos nos ratos alimentados com dieta de caseína comparado com os ratos em dieta de proteína de soro de leite. Embora os níveis de colesterol sérico total e de HDL-colesterol tivessem sido idênticos nos grupos alimentados com proteína de soro, soja ou de girassol, a excreção fecal de esteróis neutros foi maior para o grupo em proteína de soja. Por outro lado, o colesterol hepático foi significativamente mais baixo nos ratos em dieta com proteína de soro, comparado com as demais dietas estudadas.

Os autores desta pesquisa concluíram que, comparado com a dieta de caseína, a dieta com proteína de soro provocou uma redução no colesterol total e do HDL-colesterol, sem interferir na excreção de esteróides neutros. Por outro lado, as dietas de soja e girassol diminuíram os níveis de HDL-colesterol sangüíneo, sendo que apenas a dieta de soja promoveu um aumento da excreção fecal de esteróides.

Em outro estudo, Nagaoka et al. ${ }^{45}$, em pesquisa com ratos compararam os efeitos da proteína de soja com as do soro de leite e verificaram que os níveis de lipídios totais e de colesterol foram significativamente diminuídos pelo efeito das proteínas de soro, sendo que o efeito para as proteínas de soro foi mais significativo que para as proteínas de soja.

Outro aspecto das proteínas de soro de leite, que pode contribuir para a saúde cardiovascular, está relacionado à descoberta de que a hidrólise enzimática de algumas dessas proteínas liberam peptídios com ação hipotensora ou antihipertensiva ${ }^{46-48}$. Esses peptídios que podem ser formados também a partir de outras proteínas alimentares (soja, peixe, trigo, gelatina) são capazes de inibir a ação da enzima conversora 
de angiotensina I em angiotensina II (ACE). A angiotensina I é um decaptídio inativo produzido nos rins, que é convertido em angiotensina II, um octapeptídio com forte ação vasoconstritora, portanto, com ação hipertensora. Além da ação hipertensora, a angiotensina II estimula a produção do hormônio aldosterona que age diminuindo a excreção renal de fluido e de sais, aumentando a retenção de água e o volume de fluido extracelular. Vários peptídios com ação inibidora da ACE foram isolados e caracterizados a partir de hidrolisados da $\beta$-lactoglobulina e da $\propto$-lactalbumina ${ }^{49-52}$.

As proteínas do soro de leite poderão exercer vários efeitos benéficos sobre o sistema cardiovascular graças às suas propriedades redutoras (cisteína, estímulo à síntese de glutationa), seqüestrantes de radicais livres (glutationa, lactoferrina, lactoperoxidase) que são também inibidores da lipoxidação das lipoproteínas e artérias. Peptídios derivados da lactoferrina mostraram atividade anticoagulante, inibindo a agregação de plaquetas ${ }^{53}$.

\section{Benefício à atividade esportiva}

O exercício físico tem profundo efeito no metabolismo das proteínas ${ }^{54}$, no consumo de $\mathrm{O}_{2}$ $\left(\mathrm{VO}_{2}\right)$ acima dos níveis de repouso ${ }^{55}$, no transporte de aminoácidos ${ }^{56}$ e de glicose ${ }^{57}$, bem como na concentração de lactato muscular ${ }^{58}$.

Nos últimos anos tem-se verificado um avanço importante da nutrição esportiva, com base em princípios fisiológicos e bioquímicos ${ }^{59}$. Uma alimentação especial pode promover melhor saúde e otimizar os benefícios do treinamento.

Sabe-se que aminoácidos e peptídios, como precursores da síntese protéica, exercem papel fundamental no organismo. Tem-se observado que a oxidação da leucina, em ratos treinados, é superior à de ratos não treinados ${ }^{60}$, portanto, o condicionamento físico aumenta o turnover e a oxidação da leucina e essa oxidação é acelerada na media em que o organismo esteja mais depletado de glicogênio.
O exercício físico, em geral, requer um maior aporte protéico, o que se deve a uma maior utilização de aminoácidos como fonte energética no metabolismo. Na atividade física, a diminuição da disponibilidade de aminoácidos pode limitar o efeito estimulatório da insulina sobre a síntese tecidual de proteínas ${ }^{61}$. Excessos na ingestão de proteínas podem, contudo, proporcionar efeitos negativos no metabolismo hepático e renal.

Estudos com animais de laboratório, exercitados à exaustão, utilizando dietas com proteínas de soro de leite ou seus hidrolisados, levaram a conclusões ligeiramente diferentes em função do tipo de dieta usada.

Tassi62, utilizando proteína de soro com $15 \%$ de grau de hidrólise, observou que ratos submetidos a exercício exaustivo foram capazes de manter os teores séricos de glicose e albumina e do glicogênio muscular. Por outro lado, Ramos ${ }^{63}$, utilizando um hidrolisado protéico de soro lácteo, com 30\% de grau de hidrólise não observou o mesmo efeito protetor observado na pesquisa anterior. Provavelmente o hidrolisado com 30\% de grau de hidrólise não tenha sido tão bem absorvido e metabolizado quanto o de menor grau de hidrólise (15\%).

Dieta suplementada com mistura de proteínas de soro lácteo, parcialmente hidrolisadas e carboidrato foi capaz de estimular a secreção de insulina e aumentar os níveis de aminoácidos plasmáticos com maior eficiência que dietas suplementadas com proteína intacta (não hidrolisada) ou com apenas carboidrato ${ }^{64}$.

Estudos realizados em Campinas, SP, utilizaram ratos Wistar jovens recebendo dois tipos de dieta, proteína de soro isolada ou um hidrolisado (grau de hidrólise médio) resultante do mesmo isolado, submetidos a três condições experimentais: grupo sedentário, grupo treinado e grupo treinado à exaustão65,66. Foram avaliados a evolução ponderal tempo de exaustão, concentração de lactato sangüíneo, glicose, albumina e proteínas totais séricas, além de glicogênio e proteína muscular. Os resultados mais relevantes neste estudo mostraram que a proteína hidrolisada 
promoveu melhor desempenho físico nos animais treinados, evidenciado pela maior resistência à exaustão; o hidrolisado produziu redução do lactato sangüíneo e apresentou vantagem significativa quanto à manutenção dos níveis de albumina e de proteínas séricas totais. Foi possível inferir, desta pesquisa, que o grupo de animais em dieta de hidrolisado de proteínas de soro tiveram melhor desempenho metabólico e foram significativamente mais resistentes à exaustão que os ratos que receberam a dieta com proteínas de soro íntegras (não hidrolisadas).

Considerando que o exercício físico exaustivo causa depressão imunológica ${ }^{67,68}$, produção de radicais livres e catabolismo protéico e que as proteínas do soro de leite e seus hidrolisados agem estimulando o sistema imune (celular e humoral) através do estímulo linfocitário e produção de anticorpos; que várias proteínas do soro de leite e seus produtos metabólicos são antioxidantes e seqüestrantes de radicais livres, que essas proteínas são rapidamente digeridas e absorvidas e que a composição de aminoácidos das mesmas favorecem a síntese de proteínas musculares (aminoácidos de cadeias ramificadas) é de se esperar que sua ação seja altamente benéfica ao organismo humano e animal, antes, durante e após períodos de exercícios intensos e/ou prolongados.

\section{Outros benefícios}

Os conhecimentos sobre os mecanismos de ação fisiológica das proteínas do soro de leite são ainda muito incompletos, particularmente pouco se conhece sobre as funções e os benefícios de inúmeros componentes menores (natureza protéica ou não-protéica) presentes no soro e recuperados em maior ou menor proporção nos isolados protéicos.

No conjunto, essas substâncias têm sido chamadas de fatores de crescimento celular, incluindo neste grupo, além da lactoferrina ${ }^{18}$, uma série de polipeptídios, incluindo os fatores de crescimento semelhantes à insulina I e II (IGF-I e IGF-II), fatores ácidos e básicos de estímulo ao crescimento de fibroblastos (aFGF, bFGF), fatores de transformação de tecidos (TGF- $\beta_{1}$ e TGF- $\beta_{2}$ ), além de vários outros não identificados ${ }^{69}$. No conjunto, essas substâncias estimulam a proliferação (mitogênese) de variados tipos de células, podendo substituir, em boa parte, o soro fetal bovino comercializado com esta finalidade. Pesquisadores australianos ${ }^{69}$ estabeleceram metodologias em nível piloto, para o isolamento desses fatores do soro de leite, como um concentrado, estudando sua ação não somente como estimulador do crescimento celular, mas também, como agente reparador de feridas crônicas $^{70}$. Um extrato total desses fatores de crescimento estimulou o crescimento de fibroblastos com potência várias vezes maior que o observado para o soro fetal bovino. Demonstrou-se ainda que cada um desses fatores isoladamente não estimulou a multiplicação e o crescimento celular, sugerindo que deve ser o efeito sinergístico do conjunto dos fatores que produz o resultado desejado.

Pesquisa recente ${ }^{71}$ demonstrou a eficácia do permeado da ultrafiltração do soro de leite como fator de crescimento em meios de cultura de Lactobacillus acidophilus e Bifidobacterium lactis, probióticos utilizados na formulação de alimentos funcionais.

É ainda oportuno citar que a $\propto$-lactalbumina faz parte do complexo enzimático responsável pela síntese da lactose na glândula mamária, portanto muito importante no processo de síntese e excreção da lactose, um dos principais componentes do leite.

Pelo seu elevado teor de triptofano, a $\propto$-lactalbumina tem o poder de elevar o triptofano sangüíneo. Sendo o triptofano precursor do neurotransmissor serotonina e do hormônio neurosecretor melatonina, alguns autores ${ }^{72,73}$ atribuíram efeitos comportamentais da ingestão dessa proteína no apetite, na saciedade, no humor, na percepção da dor e no ciclo de dormir e acordar. 


\section{CONSIDERAÇÕES FINAIS}

Avanços recentes nas Ciências da Nutrição e nas pesquisas biomédicas, têm revelado algumas das complexas relações entre nutrição e saúde, sugerindo que algumas proteínas e peptídios de origem alimentar poderão ter utilidade na prevenção e/ou tratamento de condições patológicas decorrentes da má nutrição, doenças e envelhecimento.

Apesar das inúmeras pesquisas mostrando efeitos fisiológicos benéficos das proteínas e peptídios do soro de leite, particularmente, em experimentos com animais, o conhecimento ainda é muito limitado sobre esses efeitos no organismo humano. Muito há que se pesquisar sobre os verdadeiros mecanismos de ação dessas proteínas e peptídios e das quantidades que devem participar da dieta para produzir seus efeitos benéficos.

Muitas das propriedades funcionais fisiológicas descritas nesta revisão estão condicionadas à manutenção da integridade estrutural dessas proteínas, significando que métodos especiais de produção devem ser adotados para a preservação das estruturas das proteínas e de suas propriedades.

É animador verificar que pesquisadores, nutricionistas e processadores de alimentos vêm reconhecendo que essas proteínas e peptídios delas derivados, poderão ter um alto valor no mercado e constituir-se em suplementos alimentícios valiosos na diminuição de riscos de doenças crônicas e degenerativas, bem como valiosos aliados dietoterápicos no tratamento de várias doenças.

\section{REFERÊ NCIAS}

1. Sgarbieri VC. Proteínas em alimentos protéicos: propriedades-degradações-modificações. São Paulo: Varela; 1996. 517p.

2. Zinsly PF, Sgarbieri VC, Pereira Dias NFG, Jacobucci $H B$, Pacheco MTB, Baldini VLS. Produção piloto de concentrados de proteínas de leite bovino: composição e valor nutritivo. Braz J Food Tecnol 2001; 4:1-8.

3. Maubois J-L, Fauquant J, Famelart M-H, Caussin F. Milk microfiltrate, a convenient starting material for fractionation of whey proteins and derivatives. In: Proceedings of the 3rd International Whey Conference; 2001; Munich. Chicago: American Dairy Products Institute; 2001. p.59-72.

4. Hambreus L. Nutritional aspects of milk proteins. In: Fox PL, editor. Advanced Dairy Chemistry. London: Elsevier; 1992. v.1:Proteins, p.457.

5. Heng GB. Chemical composition of bovine colostrum. Food for Health in the Pacific Rim. Trumball (Conn): Food and Nutrition Press; 1999. p.405.

6. Boirie $Y$, Dangin M, Gachon P, Vasson MP, Maubois $J-L$, Beaufrère B. Slow and fast dietary proteins differently modulate post-prandial protein secretion. Proc Nat Acad Sci (USA) 1997; 94: 14930-5.

7. Frühbeck G. Slow and fast dietary proteins. Nature 1998, 39:843-5.

8. Dangin M, Boiurie $Y$, Garcia-Rodena $C$, Gachon $P$, Fauquant J, Callier $\mathrm{P}$, et al. The digestion rate is an independent regulating factor of post prandial protein retention. Am J Physiol Endocrin Metab 2001; 280:E340-E8.

9. Bounous $G$, Kongshavn PAL. Influence of dietary protein on the immune system of mice. J Nutr 1982; 112:1747-55.

10. Bounous G, Létourneau L, Kongshavn PAL. Influence of dietary protein type on the immune system of mice. J Nutr 1983; 113:1415-21.

11. Bounous G, Kongshavn PAL, Gold P. The immunoenhancing property of dietary whey protein concentrate. Clin Invest Med 1988; 11:271-8.

12. Bounous $G$, Batist $G$, Gold P. Immunoenhancing property of dietary whey protein in mice: role of glutathione. Clin Invest Med 1989; 12:154-61.

13. Bounous G, Gold P. The biological activity of undenatured dietary whey proteins: role of glutathione. Clin Invest Med 1991; 14:296-309. 
14. Bounous G, Baruchel S, Falutz J, Gold P. Whey protein as a food supplement in HIV-seropositive individuals. Clin Invest Med 1993; 16:204-9.

15. Bounous G. Immuno-enhancing properties of undenatured milk serum protein isolate in HIV patients. Proc Int Dairy Fed 1998, Brussels, Belgium, p.293-305.

16. Sgarbieri VC, Rangel HA, Zinsly PF, Pacheco MTB, Pereira Dias NFG. Novel Nutritional and Physiological Functions of Milk Proteins. In: Proceedings of the 4th International Conference of Food Science and Tecnology 2000; Wuxi, China. Wuxi: University of Light Industry/National Association of Food; 2000. p.196-209.

17. Moreno YMF. Influência das proteínas do soro de leite bovino no estado nutricional, composição corporal e sistema imune em coorte de crianças com síndrome da imunodeficiência adquirida (AIDS) [dissertação]. Campinas: Faculdade de Engenharia de Alimentos, Universidade Estadual de Campinas; 2002.

18. Walzem RL, Dillard CJ, German JB. Whey components: Millenia of evolution create functionalities for mammalian nutrition: what we know and what we may be overlooking. Crit Rev Food Sci Nutr 2002; 42:353-75.

19. Dairy Council Digest. Emerging health benefits of whey. 2003 Nov./Dec. [cited 2004 Sept 25]; 74(6). Available from: www.nationaldairycouncil.org

20. Nabet $P$, Linden G. Constituants bioactifs in lait, nutrition et santé. Paris: Tec. \& Doc; 2001. p.169-87.

21. Ikeda M, Sugiyama K, Tanaka T, Tanaka K, Sekihara $\mathrm{H}$, Shimotohno $\mathrm{K}$, et al. Lactoferrin markedly inhibits hepatitis $C$ virus infection in cultured hepatocytes. Biochem Biophys Res Com 1998; 245:549-53.

22. McCann KB, Lee A, Wan J. Antiviral activity of milk proteins. Aust J Dairy Tecnol 2001; 52:109-18.

23. Bellamy W, Takase M, Wakabayashi H, Kawase K, Tomita M. Antibacterial spectrum of lactoferricin $B$, a potent bactericidal peptide derived from the $\mathrm{N}$-terminal region of bovine lactoferrin. J Appl Bacteriol 1992, 73:472-8.
24. Roy MK, Kuwabara Y, Hara K, Watanabe Y, Tornai $\mathrm{Y}$. Peptides from the $\mathrm{N}$-terminal end of bovine lactoferrin induce apoptosis in human leukemic (HL-60) cells. J Dairy Sci 2002; 85:2065-74.

25. Pellegrini A, Dettling C, Thomas U, Hunziker P. Isolation and caracterization of four bactericidal domains in the bovine $\beta$-lactoglobulin. Bioch Biophys Acta 2001; 1526:131-40.

26. Pellegrini A, Thomas U, Bramaz N, Hunziker P, Von Fallenberg R. Isolation and identification of three bactericidal domains in the bovine $\propto$-lactalbumin molecule. Bioch Biophys Acta 1999; 1426:439-48.

27. Hakansson A, Zhivotovsky B, Sabharwal H, Svanborg C. Apoptosis induced by a human milk protein. Proc Nat Acad Sci (USA) 1995; 92:8064-8.

28. McIntosh GH, Royle PJ, Le Leu RK, Regester GO, Johnson MA, Gristed RL, et al. Whey protein as functional food ingredients? Int Dairy J 1998; 8:425-34

29. McIntosh GH, Regester GO, Le Leu RK, Royle PJ, Smithers GW. Dairy proteins protect against dimethylhydrazine-induced intestinal cancers in rats. J Nutr 1995; 125:809-16.

30. McIntosh GH, Le Leu RK. The influence of dietary proteins on colon cancer risk. Nutr Res 2001; 21:1053-66.

31. Dias NFGP. Propriedades imunoestimulatórias e antitumoral de concentrados protéicos do soro de leite bovino, de caseína e de um isolado protéico de soja [tese]. Campinas: Faculdade de Engenharia de Alimentos, Universidade Estadual de Campinas; 2004.

32. Hakkak R, Korourian S, Ronis M, Irby D, Kechclana $S$, Rowland $C$, et al. Dietary prevention of mammary cancer in multiparous female rats by whey protein, but not soy protein isolate. Proc Am Assoc Cancer Res 1999; 40:2010.

33. Chmiel JF. Anti-tumor effects of dietary whey protein and its value for head and neck cancer patients. In: International Dairy Federation: Proceedings of the 3rd International Whey Conference; 1997. Chicago. Brussels, Belgium: International Dairy Federation; 1998. p.310-4. 
34. Bourtourault M, Buleon R, Samperez S, Jouan P. Effect des protéines du lactosérum bovin sur la multiplication de cellules cancéreuses humaines. C R Soc Biol 1991; 185:319-23.

35. Russo A, DeGraff W, Friedman N, Mitchell JB. Selective modulation of glutathione levels in normal versus tumor cells and subsequent differential response to chemotherapy drugs. Cancer Res 1986; 26:2845-8.

36. Rosaneli CF. Atividade anti-ulcerogênica de um concentrado de soro de leite bovino em modelos experimentais em ratos [dissertação]. Campinas: Faculdade de Engenharia de Alimentos, Universidade Estadual de Campinas; 2002.

37. Rosaneli CF, Bighetti AE, Antônio MA, Carvalho $J E$, Sgarbieri VC. Efficary of a whey protein concentrate on the inhibition of stomach ulcerative lesions caused by ethanol ingestion. J Med Food 2002; 225-32.

38. Rosaneli CF, Bighetti AE, Antônio MA, Carvalho $J E$, Sgarbieri VC. Protective effect of bovine milk whey protein concentrate on the ulcerative lesions caused by subcutaneous administration of indomethacin. J Med Food 2004; 7(3). [in press].

39. Matsumoto $H$, Shimokawa $Y$, Ushida $Y$, Toida $T$, Hayasawa $H$. New biological function of bovine alpha-lactalbumin: protective effect against ethanol and stress-induced gastric mucosal injury in rats. Biosci Biotechnol Bioch 2001; 65: 1104-11.

40. Ushida Y, Shimokawa Y, Matsumoto H, Toida T, Hayasawa $H$. Effects of bovine $\propto$-lactalgumin on gastric defense mechanisms in naive rats. Biosci Biotechnol Bioch 2003; 67:577-83.

41. Mezzaroba LFH. Ação da $\propto$-lactalbumina e seus hidrolisados na inibição da úlcera gástrica induzida por diferentes agentes ulcerogênicos [dissertação]. Campinas: Faculdade de Engenharia de Alimentos, Universidade Estadual de Campinas; 2004.

42. Jacobucci HB. Influência de várias fontes protéicas nos níveis sangüíneos e hepáticos de colesterol, triglicerídeos e lipoproteínas [dissertação]. Campinas: Faculdade de Engenharia de Alimentos, Universidade Estadual de Campinas; 1999.
43. Jacobucci HB, Dias NGP, Sgarbieri VC, Borges PZ, Tanikawa C. Impact of different dietary protein on rat growth, blood serum lipids and protein, and liver cholesterol. Nutr Res 2001; 21:905-15.

44. Sautier K, Dieng K, Flament C, Doucet C, Suquet JP, Lemonnier D. Effects of whey protein, casein, soyabean and sunflower protein on the serum, tissue and faecal steroids in rats. Br J Nutr 1983; 49:313-9.

45. Nagaoka S, Kanamuru Y, Kuzuya Y, Kojima T, Tomotsu K. Comparative studies on the serum cholesterol lowering action of whey protein and soybean protein in rats. Biosci Biotech Bioch 1992; 56:1484-5.

46. Tirelli A, De Noni I, Resmini P. Bioactive peptides in milk products. Ital J Food Sci 1997; 9:91-8.

47. Takano T. Milk derived paptides and hypertension reduction. Int Dairy J 1998; 8:375-81.

48. Da Costa EL. Efeito do processamento térmico e enzimático na obtenção de hidrolisados do isolado protéico do soro de leite com atividade antihipertensiva [tese]. Campinas. Faculdade de Engenharia de Alimentos, Universidade Estadual de Campinas; 2004.

49. Hernández-Ledesma $B$, Recio I, Ramos M, Amigo $\mathrm{L}$. Preparation of ovine and caprine $\beta$-lactoglobulin hydrolysates with ACE-inhibitory activity. Identification of active peptides from caprine $\beta$-lactoglobulin hydrolysed with thermolysin Int Dairy J 2002; 12:805-12.

50. Nurminen ML, Sipola M, Kaarto H, Pihlanto-Leppälä A, Piiola K, Tossavainen O, et al. $\propto$-Lactorphin lowers blood pressure measured by radiotelemetry in normotensive rats and spontaneously hypertensive rats. Life Sci 2000; 66:1535-43.

51. Sipola M, Finckenberg P, Vapaatalo H, Pihlanto-Leppälä A, Korhonen H, Korpela R, et al. $\propto$-Lactorphin and $\beta$-Lactorphin improve arterial function in spontaneously hypertensive rats. Life Sci 2002; 71:1245-53.

52. Van der Vem C, Grupen H, Bont DBA, Voragen AGJ. Optimization of the angiotensin converting enzyme inhibition by whey protein hydrolysates using response surface methodology. Int Dairy J 2002; 12:813-20. 
53. Léonil J, Bos C, Maubois J-L, Tomé D. Protéines in lait, Nutrition et santé. Paris: Tec. \& Doc. 2001. p.45-83.

54. Tripton KD, Ferrando AA, Phillips SMJr, Doyle D, Wolfe RR. Postexercise net protein synthesis in human muscle from orally administered amino acids. Am J Physiol 1999; 276:E628-E34.

55. Bahr R, Rejersted OM. Effect of feeding and fasting on excess postexercise oxygen consumption. J Appl Physiol 1991; 71:2088-93.

56. Roy BD, Tarnopolsky MA, McDougall JD, Fowles J, Yarasheski KE. Effect of glucose supplement timing on protein metabolism after resistance training. J Appl Physiol 1997; 82:1882-8.

57. Jeukendrup $A E$, Wagenmakers $A J M$, Stegen $J H C H$, Gijsen AP, Brouns F, Saris, WHM. Carbohydrate ingestion can completely suppress endogenous glucose production during exercise. Am J Physiol 1999; 276:E672-E83.

58. Burke L. Sports foods: A new market for the food industry. Food Austr 2000; 52:405.

59. Davis JM, Bailey SP. Possible mechanisms of central nervous system fatigue during exercise. Med Sci Sports Exerc 1987; 19:S166-S71.

60. Henderson AS, Black AL, Brooks GA. Leucine turnover and oxidation in trained rats during exercise. Am J Physiol 1985; 249:137-44.

61. Biolo G, Williams BD, Fleming RYD, Wolfe RR. Insulin actin on muscle protein kinetics and amino acid transport during recovery after resistance exercise. Diabets 1999; 48:949-57.

62. Tassi EMM. Desenvolvimento de dietas para o desempenho físico. Comparação de olipeptídios de $\propto$-lactalbumina com a proteína intacta como fonte protéico-energética, no rato [dissertação]. Campinas: Faculdade de Engenharia de Alimentos, Universidade Estadual de Campinas; 1996.

63. Ramos AG. Utilização das proteínas do soro lácteo por ratos jovens [dissertação]. Campinas: Faculdade de Engenharia de Alimentos, Universidade Estadual de Campinas; 2001.

64. Van Loon LJC, Saris WHM, Verhagen $H$, Wagenmakers AJM. Plasma insulin responses after ingestion of different amino acid or protein mixtures with carbohydrate. Am J Clin Nutr 2000; 72:96-105.

65. Tassi EMM, Amaya-Farfan J, Azevedo RM. Hydrolyzed $\propto$-lactalbumin as a source of protein to the exercising rat. Nutr Res 1998; 18:875-81.

66. Pimenta FMV. Efeitos do consumo de hidrolisado das proteínas do soro lácteo no desempenho físico e no metabolismo protéico do rato exercitado [dissertação]. Campinas: Faculdade de Engenharia de Alimentos, Universidade Estadual de Campinas; 2002.

67. Smith LL. Overtraining, excessive exercise and altered immunity. Sports Med 2003; 33:347-64.

68. Elphich GF, Greenwood BN, Campisi J, Fleshner M. Increase serum nlgM in voluntarily physically active rats: a potential role for $B_{1}$ cells. J Appl Physiol 2003; 94:660-67.

69. Belford DA, Rogers ML, Regester GO, Francis GL, Smithers GW, Liepe IJ, et al. Milk-derived growth factors as serum supplements for the growth of fibroblast and epithelial cells. In Vitro Cell Dev Biol 1995; 31:752-60.

70. Regester GO, Belford DA, Goddard C, Howarth GS, Smithers GW, Copeland AC, et al. Prospective clinical application for a growth factor extract from whey: Gut disease and wound repair. In: Proceedings of the 3rd International Whey Conference; 1997; Chicago. Brussels, Belgium: International Dairy Federation; 1998. p.333-6.

71. Saron MLG. Aproveitamento do permeado do soro de leite bovino através da transformação da lactose em lactulose e como ingrediente para meios de cultura de batérias probióticas [dissertação]. Campinas: Faculdade de Engenharia de Alimentos, Universidade Estadual de Campinas; 2004.

72. Heine WE, Klein PD, Reeds PJ. The importance of $\propto$-lactalbumin in infantil nutrition. J Nutr 1991; 121:277-83.

73. Yogman MW, Zeisel SH, Roberts C. Assessing effects of serotonin precursors on newborn behaviour. J Psychiatric Res 1982; 17:123-33.

Recebido e aceito em para publicação em 1 de outubro de 2004 . 